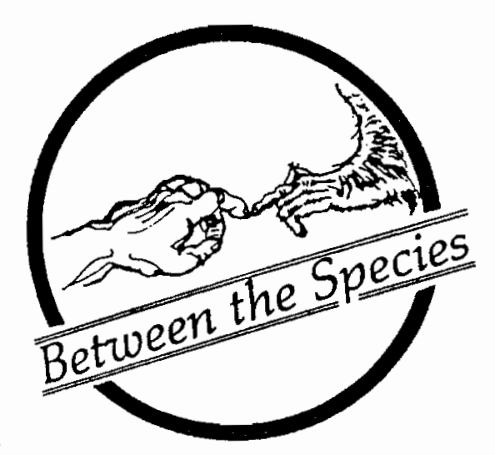

\title{
Comment on Callicott
}

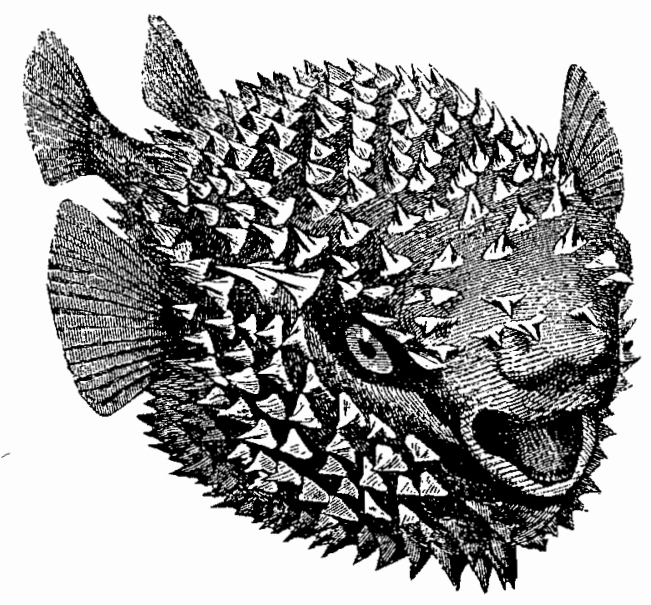

\author{
Harlan B. Miller \\ Virginia Polytechnic Institute and State \\ University
}

\section{Callicott's Aim and Argument}

In his "Animal Liberation and Environmental Ethics: Back Together Again," J. Baird Callicott attempts to reconcile the animal liberation and environmental ethics movements. Both these labels fit loosely on groups with very substantial internal diversity and even hostility, groups held together, if at all, by vague slogans. But very roughly, animal liberationists are concerned about the suffering of sentient individuals, and subscribers to environmental ethics worry about the stability and diversity of ecosystems. And these concerns can easily come into conflict.

The key to resolving, or at least minimizing, such conflict, Callicott suggests, is the notion of "community." If we construct our moral theories by generalizing some version of egoism, genuine concern for others will be perplexing, if not impossible. But if we, following Mary Midgley (and others such as Annette Baier), return to Hume's insight that sympathy is as natural as selfishness, altruism, caring for the good of others for itself, ceases to be a mystery.

Carol Belanger Graftion.
Old-fashioned Animal Cuts.

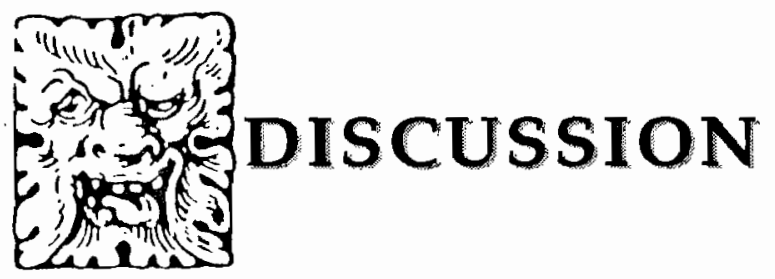


And if we then see that sympathy both creates and is created by community, we can resolve the environmental ethics/animal liberation conflict. For both are concerned with the rights and wrongs of behavior within certain communities, but different communities. Humans and domestic animals have and live in multispecies communities of affection and sympathy, and animal liberationists rightly protest the violation of the bonds of such communities by atrocities such as battery chicken farms. Environmental ethics, in contrast; is concerned with the health of biotic communities. In such communities the paramount value is the beauty, integrity, and stability of the whole community. Wild animals (and plants) are members of biotic communities, domestic animals (and plants?) are members of sympathetic or affectional communities. Different types of communities have different rules and come into conflict only at their borders. Ergo there's no real opposition between environmental ethics and animal liberation, any more than between playing the oboe and playing basketball. One can't concentrate on both at once, but they can coexist peacefully in a single life.

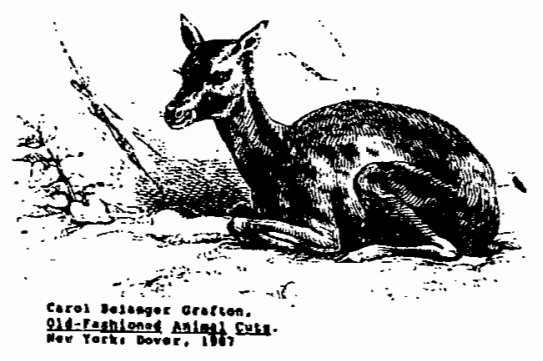

\section{Where We Agree}

The two movements have a lot of things in common, but they are mainly negative things. Both call for substantial revisions in commonsense morality, and both oppose lots of practices widely taken as routine. Packed feed lots, and the chemical monocultures that supply them, are ecological disasters as well as concentrations of suffering. Running deer with snowmobiles, draining wetlands, dumping plastics in the seas such things distress the environmentalist and the animal liberationist alike.

So we have lots of mutual enemies and lots of interests in common. But the differences run deep, and Callicott's proposal does not bridge them. A good part of the animal liberation movement would view his offer not as an olive branch but as an invitation to surrender the contested territory. And, I suspect, a good part of the environmental movement would be quite unhappy about the moral standing he seems to grant to domesticated animals - but I won't investigate that further.

\section{The Ambiguity of "Community"}

The word "community" is importantly ambiguous in this paper. On the one hand we have communities such as a band of hunter-gatherers and "their" dogs, or, as the newspapers say, "a small farming community," or, at the bottom of the size scale, a nuclear family like mine, three humans, two cats. These are communities of concern, of mutual awareness, of cooperation. I shall call these "affectional" communities. Wolf packs and, apparently, pilot whale pods are affectional communities. It is in such communities that, at a deep and fairly primitive level, we live and move and have our being.

Affectional communities are necessarily of limited size. Humanity, all five billion members, is much too large to be a single affectional community. We rightly treat it as a community in an extended sense because it consists of many, many overlapping affectional communities and because it is possible for any of its members to stand in affectional relations with any other.

But biotic communities are almost never like this. Biotic communities are bound together by colocation and mutual exploitation. Many of the 'members' (so-called) of such communities are incapable of any sort of awareness, and many that are aware of something are not aware of one another. Biotic communities just cannot (in general) be affectional communities. There is of course etymological reason why the same word is applied to both types of community, as there is etymological reason why the Republican Party and a child's birthday party are both called "party."

\section{Individuals and Species}

The laboratory beagle, purpose-bred at Charles River Labs, has never been part of a multispecific affectional community. She's not a wild animal. Does she have a certain sort of moral standing because she's a member of a species many members of which are and have been members of affectional communities with humans? Are we to take it that there is a sort of implicit contract between species? 
Contract theories are likely to seem mysterious in any case; a contract the parties to which are abstract entities is mystery on stilts.

If the lab beagle is a worthy object of moral concern, and she is, it can't be because of her history of human companionship. Callicott, I take it, has to find a difference in moral standing between this beagle and a wild raccoon in a trap. I just don't see it. (Notice that I have arranged that both beagle and raccoon are suffering through human action.)

\section{Communities and Individuals}

Callicott just accepts the undefended assertion that the beauty, integrity and stability of the biotic community are morally prior to the interests of the members of the community. I have always found this claim quite implausible. It is usually not supported by anything more than a quotation from Aldo Leopold, who offers no argument. I've never understood what is meant by 'integrity' in this context, other than stability. Nor do I understand why stability should be considered valuable in something as inherently changeable and adaptive as an ecosystem. That leaves beauty, and I'm for that, other things being equal. The "ecosystem" (I know it will be denied to be one) of the surface of the moon is beautiful and quite stable. I suppose it's got integrity.

These are very big and very deep questions, and I haven't here done anything more than trot out intuitions that conflict with Callicott's. I hope to do more along these lines elsewhere soon. My point here is just that the intuition of the moral priority of biotic community is certainly not universally shared by those who've thought about it.

Could a corresponding claim be made about affectional communities? Yes, it's been done. The supposed priority of the family's interests to those of any of its members has kept many a woman in subjection in many times and places. In politics the assignment of an overwhelming priority to community interests constitutes fascism.

\section{Evolution and Obligation}

Callicott neatly states the argument, in Darwin and others, that altruism emerges within limited groups because such behavior by individuals enhances the overall likelihood of survival of members of the group. Just how this works, and how it should best be described, is a matter of controversy into which, fortunately, we need not enter.

Evolution, if we personify it, of course has its reasons for caring more about the group than the individual, discounting infirmities that occur after reproductive age, and so on. But so what? Evolutionary reasons are not ipso facto moral reasons.

That altruism emerged within limited groups is almost certainly true. But that is no reason to argue that altruism should remain confined to such groups. Color vision probably became entrenched in our ancestors because of its utility in distinguishing safe from dangerous food. But it surely does not follow that we should use our color vision for nothing else. It is neither wicked nor foolish to rely on color vision in enjoying landscapes or creating art. Sympathy emerged in us in the pack, it emerges in us individually in the nursery. But we can carry it with us wherever we go.

\section{Sympathy and Principle}

Reflection on affectional community, as in Midgley and Hume and in Wittgenstein and Strawson, shows that moral (and epistemological) solipsism is incoherent. We understand our own desire and aversion, joy and sorrow, only as and in understanding and ascribing those states to others. But to extend concern beyond our immediate affectional community requires the recognition of the universal importance of qualities (such as sentience) we can only feel close up. Thus universal principles have their origins in sympathy and affectional community but far out-run those origins as we (both individuals and societies) grow. Our hearts cannot encompass the world, but our heads can see that what the heart cares for extends beyond the limits of the heart's vision.

In particular, our relations with animals in affectional communities make it impossible for us to deny sentience and enjoyment and suffering to them and to any other animals relevantly similar. One learns what human life (one's own included) is like only through relations with specific individuals (mother first, usually). But this knowledge grows into wider affectional communities and then beyond them in that moral maturity that extends regard and respect to all humans. And one learns what sentient life in a broader sense (one's own included) is like 
through relations with specific individuals (these days very likely a cat or a dog). This knowledge too grows wider and can come to extend regard and respect to all sentient life.

Callicott nicely characterizes part of Hume's view when he says that the "kind affections are the soil in which our morals are rooted and from which they take their nourishment." Quite so. But the plant grows far above the soil. Hume does not limit our moral concern to those close enough to elicit feelings of sympathy.

\section{Wild and Domestic}

I will be brief about one last area of disagreement. I don't think that the wild animal/domestic animal distinction will do much to reduce conflicts between environmental ethics and animal liberation. Suppose we have to choose between actions of which one would endanger a rare species by killing some number of them and the other would kill larger numbers of a quite common species. Suppose all other considerations equal, including suffering per individual killed. Here the different ethics would pull in opposite directions, assuming that environmental ethics assigns value to the preservation of species per se. (It need not, and there is plenty of room here for disagreement within the environmental ethics camp.)

A different sort of puzzle arises in cases of imported wild species (rabbits in Australia) and feral animals. The wild horses and burros of the West and feral cats all over the world seem in many ways clearly wild animals like any others, but they are of domesticated species and can transform biotic communities.

\section{Where I Agree}

I will close this long comment by setting aside the role of defender of animal liberation and commenting on two points at which I personally agree with Callicott's criticisms.

First predation. I agree that we have not the slightest obligation to interfere with or to try to restrict the predation of the wild on the wild. Further, I think that there should be strict limits on our activities of "predator control" to limit predation of the wild on the domestic. Shooting a fox attacking one's chickens is acceptable; trapping the fox in the woods or poisoning a carcass is not. That deer eat some of my garden is just a cost of having a garden.

But I am not a predator, and I believe that sport hunting is just wrong. These positions are not easy to reconcile, and worse is to come. My cats hunt, especially one of them. I wish he wouldn't, and I've put a loud bell on him (he likes it), and I fairly frequently warn birds away and rescue voles and deer mice. I could have the cat declawed or tie his legs together or keep him indoors (as I certainly would if we lived in the city), but I don't. I don't because he seems so clearly to be attaining something like cat eudaimonia, to be living as a cat should.

I'm not happy with my stand on predation, but it seems to be the best I can do. Our primary duty to animals, I think, is nonmaleficence. We should, as best we can, do them no harm and let them live their own lives of their own sorts. This of course is one factor among others. I agree to my cats hunting but not to their reproducing.

A second major point on which I agree with Callicott is the inadequacy of much (maybe all) of the animal liberation literature in dealing with the problem of partial interests. It is very difficult to construct a plausible moral theory that does justice both to justice and to loyalty and love. My partial interests in my family, my friends, my country, and so on conflict from time to time with the impartial demands on me of truth, the environment, suffering strangers, and so on. This is a real problem, as David Wong ${ }^{1}$ and others have recently insisted. It is not, however, a special problem for animal liberation theorists but a general problem in current ethical theory. We all seem to have both impartialist principles and particular loyalties, and no general reconciliation is at hand.

If the image of nested communities can really make some headway on the partial/impartial difficulty, that will be a strong argument in its favor. So far I remain skeptical.

I am also quite skeptical about the possibility of reconciling environmental ethics (at least of the variety to which Callicott subscribes) and animal liberation.

\section{Notes}

${ }^{1}$ David Wong, "Moral Realism Without Foundations," Souchern Joumal of Philosophy XXIV (Supplement, 1986), p. 95. 113. 